\title{
IgG4-Related Disease in a Patient with Uncontrolled Bronchial Asthma: Case Report and Literature Review
}

\author{
Fahad Almuhanna, Ahmad Al-Shami, Mohammad Almousa, Yaser M. Ali \\ Department of Medicine, Mubarak Al Kabeer Hospital, Kuwait City, Kuwait \\ Email: dr_bos3eed@hotmail.com
}

How to cite this paper: Almuhanna, F., Al-Shami, A., Almousa, M. and Ali, Y.M. (2020) IgG4-Related Disease in a Patient with Uncontrolled Bronchial Asthma: Case Report and Literature Review. Case Reports in Clinical Medicine, 9, 303-309.

https://doi.org/10.4236/crcm.2020.99043

Received: July 23, 2020

Accepted: September 24, 2020

Published: September 27, 2020

Copyright $\odot 2020$ by author(s) and Scientific Research Publishing Inc. This work is licensed under the Creative Commons Attribution International License (CC BY 4.0).

http://creativecommons.org/licenses/by/4.0/

\begin{abstract}
IgG4-related disease (IgG4-RD) is a multisystem autoimmune disease that can affect different organs of the body. Commonly, it affects the pancreas, salivary glands and the orbit. It is known that it can be diagnosed when there is an established correlation between clinical findings, IgG4 level and histopathology. In our case report, we present a case of a 38-year-old male patient who was suffering from uncontrolled asthma for 7 years before diagnosing him with IgG4 related disease confirmed by lacrimal gland biopsy.
\end{abstract}

\section{Keywords}

Asthma, IgG4, Autoimmune

\section{Introduction}

IgG4-related disease (IgG4-RD) is a systemic autoimmune disease, characterized by infiltration of immunoglobulin G4 (IgG4)-bearing lymphoplasmacytic cells in a variety of organ systems [1]. This disease has been observed in the pancreas, biliary tree and gallbladder, major salivary glands, ocular regions, kidneys, and even the lungs. Pulmonary manifestations include pulmonary solid nodules, thickening of bronchovascular bundles and inter-lobular septa, interstitial involvement, and round-shaped ground glass opacities [2]-[7]. There is scant evidence from cross-sectional studies that there is a connection between asthma and IgG4 disease, as one cross-sectional study has concluded that $12 \%$ of patients with proven IgG4-RD had a previous diagnosis of asthma. Upon analysis 
of some case reports of patients diagnosed with IgG4-RD and respiratory manifestations, such as a previous diagnosis of asthma, it was determined that such patients were very sensitive to trials of systemic steroids, both in terms of improvement of symptoms as well as resolution of disease pathology. In a case report from China, published by Wang et al. involving a 52-year-old male patient diagnosed with IgG4-RD, with tracheobronchial nodules and prior diagnosis of asthma, it was observed than upon administration of prednisone, the infiltration of IgG4 positive cells decreased in the bronchial mucosal biopsy specimens of the above patient [8].

The case that we are discussing also involves a young gentleman of 38 years of age, with a prior history of asthma, that was difficult to control with regular inhaled corticosteroids, and frequently requiring systemic steroids. He also has a recurrent history of sinusitis, as well as an acute complaint of ocular swelling, both of which are features that have been demonstrated to be related to patients with a diagnosis of IgG4-RD. In a study conducted to analyze the association between chronic rhino-sinusitis (CRS) and systemic symptoms in patients meeting the diagnostic criteria of IgG4 disease, it was concluded that patient with CRS was more likely to exhibit ocular symptoms, such as periorbital swelling [9].

\section{Case Report}

Mr. A.K is a 38-year-old male from Kuwait, a known case of Bronchial Asthma, nasal polyps and sinusitis for the last 7 years. He has been having difficulties controlling his asthma despite being compliant with his asthma medication. Our patient had multiple visits to the emergency department requiring intramuscular steroids to help in easing his symptoms during the past seven years. Mr. A.K was even kept on Omalizumab (a monoclonal antibody) for 4 months as is indicated in his condition. He presented to us after noticing a periorbital edema alongside submandibular and parotid glands enlargement, which only bothered him lately. It was noticed that during short periods of corticosteroids the swellings were improved. Mr. A.K also noticed that he had easy fatigability and lack of energy. The patient was never a smoker nor exposed to secondhand smoking, he had no skin allergies nor food allergies. No epistaxis, hemoptysis, weight loss, fever, anorexia or gastrointestinal symptoms.

Vitals within normal limits; Physical examination showed bilateral swelling which is in periorbital region alongside bilateral parotid enlargement. Lymph node exam showed absent lymphadenopathy. Chest, Cardiovascular and Abdominal examination within normal limits. Rest of the systemic exam was normal.

The patient underwent a number of initial basic investigations, including:

A 12 lead ECG, showing a normal sinus rhythm; Chest X-ray Showing Bilateral Hilar lymphadenopathy, increased vascular markings (Figure 1), as well a complete blood count, shown in Table 1 . 


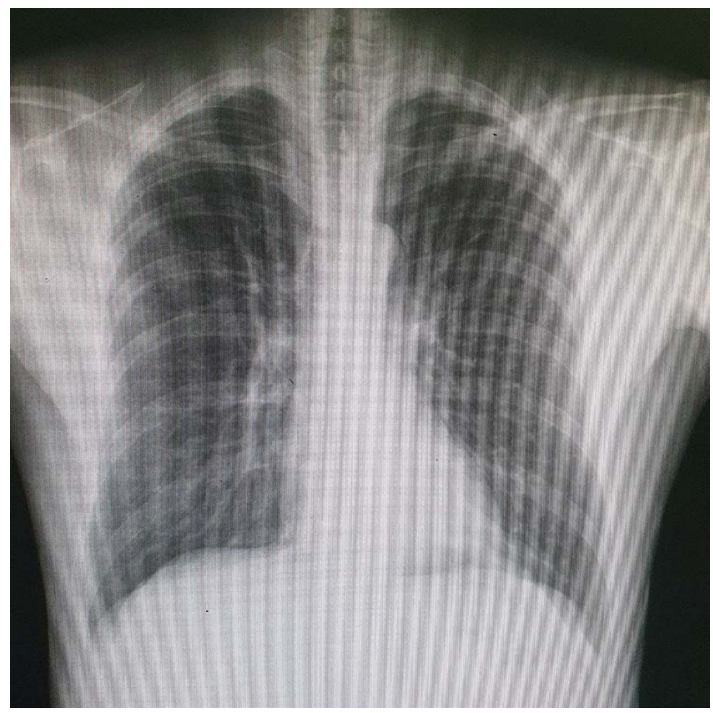

Figure 1. Chest X-ray shows bilateral hilar lymphadenopathy, increased vascular markings (from patient own medical records).

Table 1. Complete blood count result (from patient own medical records).

\begin{tabular}{ccc}
\hline White Blood Cell (WBC) & $5.41 \times 10^{9} / \mathrm{L}$ & $3.7-10$ \\
Hemoglobin & $160 \mathrm{~g} / \mathrm{L}$ & $130-170$ \\
Mean corpuscular volume (MCV) & $89.5 \mathrm{fL}$ & $83-101$ \\
Mean corpuscular hemoglobin (MCH) & $24 \mathrm{pg}$ & $27-32$ \\
Platelets & $260 \times 10^{9} / \mathrm{L}$ & $130-430$ \\
Neutrophil & $2.4 \times 10^{9} / \mathrm{L}$ & $1-7.6$ \\
Lymphocytes & $1.6 \times 10^{9} / \mathrm{L}$ & $1-3$ \\
Eosinophils & $0.7 \times 10^{9} / \mathrm{L}$ & $0.02-0.5$
\end{tabular}

Glucose, Urea, Creatinine, Electrolytes, Liver Enzymes, Albumin, Lipid Panel, Thyroid Function, Coagulation Profile all within normal limit. Lipase and Amylase were normal. Rheumatoid Factor 20 IU/L. Erythrocyte sedimentation rate ESR $12 \mathrm{~mm} / \mathrm{hr}$. C-Reactive Protein (CRP) $11.0 \mathrm{mg} / \mathrm{L}$. Hepatology screening for Hepatitis $\mathrm{B}$ and $\mathrm{C}$ were negative. Immunology screen was negative Antinuclear antibody, antiproteinase 3 Antibody, anti-Myeloperoxidase antibody, Antineutrophil cytoplasmic antibody and Anti-C1q Antibody. Normal Complement count. Ultrasound abdomen shows a nonspecific thickening of gallbladder wall. Based on the presentation a Lacrimal Biopsy was performed and an IgG4 staining was done and confirmed positive. The patient also had an immunoglobulin panel prior to his treatment, shown in Table 2, which demonstrated a high level in a number of immunoglobulin subclasses.

The patient was started on Rituximab, and has been in a stable condition for 2 years since starting his treatment. Table 3 shows the results of the immunoglobulin panel 2 years after the initiation of his treatment. The patient has been doing fine with the treatment and his asthma has been well controlled as 
Table 2. Immunoglobulin levels result before treatment, September/2014 (from patient own medical records).

\begin{tabular}{ccc}
\hline IgG & $24.1 \mathrm{~g} / \mathrm{L}$ & $6-16$ \\
$\operatorname{IgA}$ & $0.72 \mathrm{~g} / \mathrm{L}$ & $0.8-2.8$ \\
$\operatorname{IgM}$ & $0.361 \mathrm{~g} / \mathrm{L}$ & $0.5-1.9$ \\
$\operatorname{IgG} 1$ & $6490 \mathrm{mg} / \mathrm{L}$ & $3824-9286$ \\
IgG2 & $9710 \mathrm{mg} / \mathrm{L}$ & $2418-7003$ \\
IgG3 & $>1860 \mathrm{mg} / \mathrm{L}$ & $218.2-1761$ \\
IgG4 & $>1440 \mathrm{mg} / \mathrm{L}$ & $39-864$ \\
\hline
\end{tabular}

Table 3. Immunoglobulin levels result after treatment, May/2019 (from patient own medical records).

\begin{tabular}{ccc}
\hline IgG & $13.3 \mathrm{~g} / \mathrm{L}$ & $6-16 \mathrm{~g} / \mathrm{L}$ \\
$\operatorname{IgA}$ & $1.16 \mathrm{~g} / \mathrm{L}$ & $0.8-2.8 \mathrm{~g} / \mathrm{L}$ \\
$\operatorname{IgM}$ & $0.373 \mathrm{~g} / \mathrm{L}$ & $0.5-1.9 \mathrm{~g} / \mathrm{L}$ \\
$\operatorname{IgG} 1$ & $4470 \mathrm{mg} / \mathrm{L}$ & $3824-9286$ \\
IgG2 & $5820 \mathrm{mg} / \mathrm{L}$ & $2418-7003$ \\
IgG3 & $2640 \mathrm{mg} / \mathrm{L}$ & $218.2-1761$ \\
IgG4 & $1662 \mathrm{mg} / \mathrm{L}$ & $35-1761$ \\
\hline
\end{tabular}

per symptom check and with using the Asthma Control Test (ACT). The Patient has also continued on budesonide and formoterol fumarate dihydrate alongside Fluticasone propionate. The patient has been better in terms of the ACT score and also Lab results showed improved Ig titer and specific Immunoglobulin count (Table 3). Mr. A continued to follow in the clinic to receive Rituximab once per six months. At this point, the patient's visit to the Emergency Department has decreased. He has not been taking oral corticosteroids nor Omalizumab. Mr. A still takes short acting beta-agonist alongside inhaled steroids.

\section{Discussion}

It is important to mention that IgG4-related disease can be related to respiratory system and even manifested initially with history of allergic rhinitis and symptoms of uncontrolled bronchial asthma as in our patient which is actually found in $40 \%-50 \%$ of cases of IgG4-related diseases [10] [11] [12] [13]. Patients can be asymptomatic or have different respiratory symptoms such as: cough, dyspnea, hemoptysis or pleuritic chest pain. Patients with autoimmune pancreatitis can even present a picture of interstitial pneumonia [14]-[19]. After thorough assessment of different IgG4-related cases, it was found that their Lung involvement can be categorized in four manifestations: solid nodular, Bronchovascular, interstitial and ground-glass opacities [20] [21].

Interestingly, in different cases of pulmonary involvement, it has been found that it can mimic sarcoidosis manifestation. That was evident in Patients' CT 
Chest that has bilateral hilar lymphadenopathy or lung nodules [22]. Also, during bronchoscopy, they found edematous hypervascular bronchial mucosa as in sarcoidosis [21] [22]. In other aspects, pulmonary involvement has been reported as extrinsic compression of the central airways due to fibrosing mediastinitis and bronchiectasis [21] [22].

In a different presentation, as found in our case, Salivary glands involvement is very common in IgG4-related disease. It can be lacrimal, parotid or submandibular gland that is affected in a combination. Our patient presented with parotid gland involvement which is part of a syndrome called "Mikulicz syndrome" [23].

\section{Conclusion}

A regular course of Rituximab every six months found to be effective in our case and resulted in dramatic response of his IgG4-related asthma as per symptom and asthma control test. Early diagnosis and connection of the patient's asthma and IgG-4 disease will result in early introduction of affected drugs for better outcome.

\section{Acknowledgements}

The authors wish to thank Dr. Yaser Mustafa, consultant of rheumatology in Mubarak hospital, and all the members of Rheumatology Department.

\section{Conflicts of Interest}

The authors declare that they have no conflicts of interest.

\section{References}

[1] Hamano, H., Kawa, S., Hourichi, A., Unno, H., et al. (2001) High Serum IgG4 Concentrations in Patients with Sclerosing Pancreatitis. The New England Journal of Medicine, 344, 732-738.

[2] Zen, Y. and Nakanuma, Y. (2010) IgG4-Related Disease: A Cross-Sectional Study of 114 Cases. The American Journal of Surgical Pathology, 34, 1812-1819.

[3] Inoue, D., Zen, Y., Abo, H., Gabata, T., Demachi, H., Kobayashi, T., et al. (2009) Immunoglobulin G4-Related Lung Disease: CT Findings with Pathologic Correlations. Radiology, 251, 260-270. https://doi.org/10.1148/radiol.2511080965

[4] Ito, S., Ko, S.B., Morioka, M., Imaizumi, K., Kondo, M., Mizuno, N., et al. (2012) Three Cases of Bronchial Asthma Preceding IgG4-Related Autoimmune Pancreatitis. Allergology International, 61, 171-174. https://doi.org/10.2332/allergolint.11-CR-0352

[5] Inoue, M., Nose, N., Nishikawa, H., Takahashi, M., Zen, Y. and Kawaguchi, M. (2007) Successful Treatment of Sclerosing Mediastinitis with a High Serum IgG4 Level. General Thoracic and Cardiovascular Surgery, 55, 431-433. https://doi.org/10.1007/s11748-007-0154-2

[6] Choi, I.H., Jang, S.H., Lee, S., Han, J., Kim, T.S. and Chung, M.P. (2014) A Case Report of IgG4-Related Disease Clinically Mimicking pleural Mesothelioma. $\mathrm{Tu}_{-}$ berculosis and Respiratory Diseases, 76, 42-45. 
https://doi.org/10.4046/trd.2014.76.1.42

[7] Ishida, A., Furuya, N., Nishisaka, T., Mineshita, M. and Miyazawa, T. (2014) IgG4-Related Pleural Disease Presenting as a Massive Bilateral Effusion. Journal of Bronchology \& Interventional Pulmonology, 21, 237-241. https://doi.org/10.1097/LBR.0000000000000082

[8] Wang, X.L., Wan, J., Zhao, L., Da, J.P., Cao, B. and Zhai, Z.G. (2019) IgG4-Related Disease with Tracheobronchial Military Nodules and Asthma: A Case Report and Review of the Literature. BMC Pulmonary Medicine, 19, 191.

[9] Gao, Y., Zheng, M., Cui, L., Chen, N., Wang, Y.N., Zhan, Y.T. and Wang, Z.-G. (2018) IgG4-Related Disease: Association between Chronic Rhino-Sinusitis and Systemic Symptoms. European Archives of October-Rhino-Lanyngology, 275, 2013 2019.

[10] Matsui, S., Taki, H., Shinoda, K., Suzuki, K., Hayashi, R., Tobe, K., et al. (2012) Respiratory Involvement in IgG4-Related Mikulicz's Disease. Modern Rheumatology, 22, 31-39. https://doi.org/10.3109/s10165-011-0504-x

[11] Wallace, Z.S., Deshpande, V., Mattoo, H., Mahajan, V.S., Kulikova, M., Pillai, S. and Stone, J.H. (2015) IgG4-Related Disease: Clinical and Laboratory Features in One Hundred Twenty-Five Patients. Arthritis \& Rheumatology, 67, 2466-2475. https://doi.org/10.1002/art.39205

[12] Yamada, K., Yamamoto, M., Saeki, T., Mizushima, I., Matsui, S., Fujisawa, Y., et al. (2017) New Clues to the Nature of Immunoglobulin G4-Related Disease: A Retrospective Japanese Multicenter Study of Baseline Clinical Features of 334 Cases. Arthritis Research \& Therapy, 19, Article No. 262.

https://doi.org/10.1186/s13075-017-1467-x

[13] Zen, Y., Inoue, D., Kitao, A., et al. (2009) IgG4-Related Lung and Pleural Disease: A Clinicpathologic Study of 21 Cases. The American Journal of Surgical Pathology, 33, 1886-1893. https://doi.org/10.1097/PAS.0b013e3181bd535b

[14] Inoue, D., Zen, Y., Abo, H., et al. (2009) Immunoglobulin G4-Related Lung Disease: CT Findings with Pathologic Correlations. Radiology, 251, 260-270. https://doi.org/10.1148/radiol.2511080965

[15] Inoue, M., Nose, N., Nishikawa, H., Takahashi, Ma, Zen, Y., and Kawaguchi, M. (2007) Successful Treatment of Sclerosing Mediastinitis with a High Serum IgG4 Level. General Thoracic and Cardiovascular Surgery, 55, 431-433. https://doi.org/10.1007/s11748-007-0154-2

[16] Masaki, Y., Dong, L., Kurose, N., et al. (2009) Proposal for a new clinical entity, IgG4-Positive Multiorgan Lymphproliferative Syndrome: Analysis of 64 Cases of IgG4-Related Disorders. Annals of the Rheumatic Diseases, 68, 1310-1315. https://doi.org/10.1136/ard.2008.089169

[17] Geyer, J.T. and Deshpande, V. (2011) IgG4-Associated Sialadenitis. Current Opinion in Rheumatology, 23, 95-101. https://doi.org/10.1097/BOR.0b013e3283413011

[18] Fragoulis, G.E. and Moutsopoulos, H.M. (2010) IgG4 Syndrome: Old Disease, New Perspective. The Journal of Rheumatology, 37, 1369-1370. https://doi.org/10.3899/jrheum.100383

[19] Yamamoto, M., Takahashi, H., Sugai, S. and Imai, K. (2005) Clinical and Pathological Characteristics of Mikulicz's Disease (IgG4-Related Plasmacytic Exocrinopathy). Autoimmunity Reviews, 4, 195-200. https://doi.org/10.1016/j.autrev.2004.10.005

[20] Masaki, Y., Sugai, S. and Umehara, H. (2010) IgG4-Related Diseases Including Mikulicz's Disease and Sclerosing Pancreatitis: Diagnostic Insights. The Journal of 
Rheumatology, 37, 1380-1385. https://doi.org/10.3899/jrheum.091153

[21] Stone, J.H., Caruso, P.A. and Deshpande, V. (2009) Case 24-2009-A 26-Year-Old Woman with Painful Swelling of the Neck. The New England Journal of Medicine, 361, 511-518. https://doi.org/10.1056/NEJMcpc0902221

[22] Khosroshahi, A. and Stone, J.H. (2011) IgG4-Related Systemic Disease: The Age of Discovery. Current Opinion in Rheumatology, 23, 72-73. https://doi.org/10.1097/BOR.0b013e328341a229

[23] Geyer, J.T., Ferry, J.A., Harris, N.L., et al. (2010) Chronic Sclerosing Sialadenitis (Küttner Tumor) Is an IgG4-Associated Disease. The American Journal of Surgical Pathology, 34, 202-210. https://doi.org/10.1097/PAS.0b013e3181c811ad 